\title{
Agente penitenciário na assistência em HIV/Aids no sistema prisional: revisão de literatura
}

Correctional officers in HIV/AIDS care in the prison system: a literature review

Agente penitenciario en la asistencia al VIH/sida en el sistema penitenciario: revisión de literatura

Keila Diane Lima de Sousa ${ }^{1}$ Đi https://orcid,org/0000-0001-5230-3845

Rubia Laine de Paula Andrade ${ }^{1}$ (6) https://orcid. org/0000-0001-5843-1733

Rafaele de Oliveira Bonfim ${ }^{1}$ i h itps://orcid.org/0000-0001-8157-2323.

Nanci Michele Saita ${ }^{1}$ ib https:/orcid.orgy0000-0002-0203-2765,

Mariana Gaspar Botelho Funari de Faria ${ }^{1}$ ID https://orcid.org/0000-0002-5544-910x

Carlos Eduardo Menezes de Rezende ${ }^{2}$ it ittps://orid.org/0000-0002-5716-858X

Tereza Cristina Scatena Villa ${ }^{1}$ io hitps://orcid.org/0000-0001-8927-2624

Aline Aparecida Monroe ${ }^{1}$ id hitps://orcid.org/0000-0003-4073-2735

Como citar:
Sousa KD Andrade RL, Bonfim

Sousa KD, Andrade RL, Bonfim RO, Saita NM, Faria
MG, Rezende CE, et al. Agente penitenciário na assistência em HIV/Aids no sistema prisional: revisão de literatura. Acta Paul Enferm. 2022;35:eAPE002182.

DOI

http://dx.doi.org/10.37689/acta-ape/2022AR02183

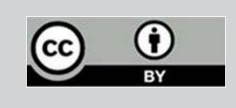

Descritores Prisões; HIV; Síndrome da imunodeficiência adquirida; Atenção à saúde; Controle de doenças transmissíveis

Keywords Prisions; HIV; Acquired immunodeficiency syndrome Delivery of health care; Communicable disease control

Descriptores

Prisiones; HIV; Síndrome de inmunodeficiencia adquirida; Atención a la salud; Control de enfermedades transmisibles

Submetido 6 de Agosto de 2020 Aceito 24 de Agosto de 2021

\section{Autor correspondente}

Aline Aparecida Monroe E-mail: amonroe@eerp.usp.br

Editor Associado (Avaliação pelos pares): Ana Lucia de Moraes Horta (https://orcid.org/0000-0001-5643-3321) Escola Paulista de Enfermagem, Universidade Federal de São Paulo, São Paulo, SP, Brasil

\section{Resumo}

Objetivo: Analisar o papel do agente de segurança penitenciária na assistência em HIV/aids no sistema prisional.

Métodos: Trata-se de uma revisão narrativa da literatura, cuja busca bibliográfica foi realizada com a utilização de vocabulários controlados e livres, derivados das palavras "agente de segurança penitenciária" e HIV/aids. 0 levantamento foi realizado nas bases de dados LILACS, MEDLINE, Embase, Cinahl e Scopus, Academic Search Premier e SocINDEX com a utilização dos operadores booleanos AND e OR. Os critérios de inclusão das produções científicas foram: estudos publicados em português, inglês e espanhol e que respondiam à questão norteadora do estudo. Excluíram-se os artigos duplicados, aqueles que não respondiam à pergunta do estudo e os estudos secundários.

Resultados: Foram recuperadas 3.036 publicações que passaram por três etapas de seleção, o que resultou em nove estudos incluídos na revisão. Quatro principais papéis desempenhados pelos agentes de segurança penitenciária na assistência em HIV/aids no sistema prisional foram identificados: regulação do acesso aos serviços médicos; colaboração e realização de atividade de prevenção à transmissão do HIV nos presídios, como distribuição de preservativos; realização de ações de educação em saúde; acompanhamento dos detentos em consultas, exames e internações externas à prisão; e planejamento de reposição de medicamentos.

Conclusão: Ao agente de segurança penitenciária, está previsto o auxílio aos profissionais de saúde na prevenção e tratamento do HIV/aids, encaminhamento e acompanhamento dos detentos aos atendimentos dentro e fora do sistema prisional, distribuição de preservativos, realização de ações de educação em saúde e ajuda na previsão de medicamentos.

\section{Abstract}

Objective: To analyze correctional officers' role in HIV/AIDS care in the prison system.

Methods: This is a narrative literature review, whose bibliographical search was carried out using controlled and free vocabularies, derived from the words "correctional officer" and HIV/AIDS. The survey was carried out in the LILACS, MEDLINE, Embase, CINAHL and Scopus, Academic Search Premier and SocINDEX databases using the Boolean operators AND and OR. Studies published in Portuguese, English and Spanish that answered the study's guiding question were included. Duplicate articles, those that did not answer the study question and secondary studies were excluded.

Results: A total of 3,036 publications were retrieved that went through three selection stages, which resulted in nine studies included in the review. Four main roles played by correctional officers in HIV/AIDS care in the prison system were identified: regulation of access to medical services; collaboration and performance of 
HIV transmission prevention activities in prisons such as condom distribution; carrying out health education actions; monitoring inmates in consultations, examinations and admissions outside the prison; and drug replacement planning.

Conclusion: Correctional officers are expected to assist healthcare professionals in HIV/AIDS prevention and treatment, referral and monitoring of inmates to care within and outside the prison system, distribution of condoms, carrying out health education actions and help in forecasting of medicines.

\section{Resumen}

Objetivo: Analizar el papel del agente de seguridad penitenciaria en la asistencia al VIH/sida en el sistema penitenciario.

Métodos: Se trata de una revisión narrativa de la literatura en la que la búsqueda bibliográfica se realizó con la utilización de vocabularios controlados y libres, derivados de las palabras "agente de seguridad penitenciaria" y VIH/sida. Se realizó el análisis en las bases de datos LILACS, MEDLINE, Embase, Cinahl y Scopus, Academic Search Premier y en SocINDEX, con la utilización de los operadores booleanos AND y OR. Los criterios de inclusión de las producciones científicas fueron: estudios publicados en portugués, inglés y español que respondían a la pregunta orientadora del estudio. Se excluyeron los artículos duplicados, los que no respondían a la pregunta del estudio y a los estudios secundarios.

Resultados: Se recuperaron 3.036 publicaciones que pasaron por tres etapas de selección, lo que resultó en nueve estudios incluidos en la revisión. Se identificaron cuatro principales papeles desempeñados por los agentes de seguridad penitenciaria en la asistencia al VIH/sida en el sistema penitenciario: regulación del acceso a los servicios médicos; colaboración y realización de actividad de prevención a la transmisión del VIH en los presidios, como la distribución de preservativos; realización de acciones de educación en salud; acompañamiento de los detenidos en consultas, exámenes e internaciones externas a la prisión; y planificación de la reposición de medicamentos.

Conclusión: Se prevé que el agente de seguridad penitenciaria auxilie a los profesionales de salud en la prevención y tratamiento del VIH/sida, encaminar y acompañar a los detenidos en las atenciones dentro y fuera del sistema penitenciario, distribución de preservativos, realización de acciones de educación en salud y ayuda en la previsión de medicamentos.

\section{Introdução}

De acordo com dados do último relatório do Programa das Naçóes Unidas para o combate ao HIV/aids, até 2018, havia 37,9 milhóes de pessoas vivendo com HIV/aids no mundo. ${ }^{(1)}$ No Brasil, de 1980 a junho de 2020, foram detectados 1.011 .617 casos de aids. ${ }^{(2)}$

Sabe-se que a população privada de liberdade (PPL) está entre as populaçōes-chave consideradas vulneráveis ao HIV, sendo relevante a presença de homens gays e homens que fazem sexo com homens, profissionais do sexo, transexuais, usuários de drogas e população prisional, per se. ${ }^{(1,3)}$ Esta última merece atenção em função do comportamento de risco desses indivíduos como: a realização de tatuagens com material alternativo, uso de drogas com material compartilhado, relaçóes sexuais desprotegidas, ${ }^{(4)}$ bem como das condiçōes do encarceramento com inadequadas situaçóes de confinamento e acesso a assistência, as quais são determinantes para a elevaçáo da vulnerabilidade ao HIV/aids no âmbito prisional. ${ }^{(5)}$ Além disso é importante considerar o perfil de vulnerabilidade social de indivíduos privados de liberdade que já não possuíam adequado acompanhamento de saúde antes de ingressarem no sistema prisional, ${ }^{(6,7)}$ o que expressa uma complexa situação de exclusão social e econômica, condicio- nada, muitas vezes, a grupos de riscos para HIV e outras infecções sexualmente transmissíveis. ${ }^{\left({ }^{(4)}\right.}$

No período de julho a dezembro de 2019, havia 8.523 casos de HIV no sistema prisional brasileiro, sendo 7.438 na população masculina e 1.085 na feminina. ${ }^{(8)}$ Ao considerar que a populaçáo prisional total era de 748.009 pessoas, ${ }^{(8)}$ a prevalência de HIV nas prisóes do país era de 11,39 casos para cada 1.000 PPL.

O direito à saúde no sistema prisional brasileiro segue orientações da Lei de Execução Penal e da Portaria Interministerial no 1777 , de 09 de setembro de 2003, que instituiu o Plano Nacional de Saúde no Sistema Penitenciário pelos Ministérios da Saúde e da Justiça. Tais dispositivos legais garantem às PPL todos os direitos preconizados pela Constituição Federal quanto ao acesso ao sistema de saúde, sendo que a assistência a esses indivíduos deve desenvolver-se a partir de açōes de atenção básica, promoção, prevenção e assistência à saúde.

Ainda é importante ressaltar que a assistência deve ser prestada por equipes interdisciplinares de saúde em unidades instaladas nos estabelecimentos prisionais e pode ser estabelecida de forma articulada aos demais pontos de atenção da Rede de Atençáo à Saúde, uma vez que tais unidades devem executar açóes compatíveis com o escopo a Atenção Primária à Saúde e algumas ações de média complexidade. ${ }^{(9)}$ 
Em relação ao HIV/aids, a sua atuação deve contemplar o diagnóstico, aconselhamento e tratamento por meio das seguintes açóes: coleta de material para realização dos exames de identificação dos casos de HIV; entrega de preservativos para detentos e profissionais do setor; redução de danos; elaboração e divulgação de materiais impressos com informações voltadas à prevenção e controle da infecção; diagnóstico de outras infecções sexualmente transmissíveis (IST); ações de vigilância e distribuição de medicaçôes para o tratamento do HIV/aids e outras IST; alimentação dos sistemas de informação de dispensação de medicamentos e de exames laboratoriais. ${ }^{(9)}$

Neste contexto, o agente de segurança penitenciária (ASP) é o profissional com escolaridade de nível médio que atua no sistema prisional, responsável pelo desempenho de atividades de vigilância, disciplina e movimentação dos detentos para outras instituiçóes prisionais ou para atendimentos fora do âmbito prisional, que zela pela integridade física e de saúde da PPL, bem como segurança da sociedade em geral. ${ }^{(10)}$

Em 2017, o quadro de profissionais do sistema prisional brasileiro era composto por 108.403 indivíduos, dos quais $74 \%$ eram servidores voltados à atividade de custódia (ASP e agente de cadeia pública) e 7,85\% eram profissionais de saúde (médicos, enfermeiros, psicólogos, assistentes sociais, dentistas, técnicos e auxiliares de enfermagem). ${ }^{(1)}$

Além do quadro de profissionais de saúde ser reduzido, ${ }^{(12)}$ o ambiente no qual os detentos estão restritos não é de acesso livre a esses profissionais $\mathrm{e}$, inclusive, estes evitam circular em determinados locais por questóes de segurança. Em função disso, o ASP se constitui como um ator chave na interlocução entre o detento e a equipe de saúde e atua com papel diferenciado no que se refere à assistência à saúde. $\mathrm{Na}$ maioria das vezes são eles que julgam a necessidade de atendimento a partir da solicitação do detento e, a depender do seu perfil ou até mesmo do seu conhecimento em saúde, pode facilitar ou dificultar este acesso. ${ }^{(13)}$

Diante do exposto, este estudo pretende analisar o papel do ASP na assistência em HIV/aids no sistema prisional.

\section{Métodos}

Realizou-se revisão narrativa da literatura, a qual constitui revisões não sistemáticas, em busca de sintetizar as informaçóes sobre determinado assunto e suas amplas perspectivas. ${ }^{(14)}$ Para a elaboração da questão de pesquisa foi utilizada a estratégia PICo, segundo descrição do The Joanna Briggs Institute (2017), ${ }^{(15)}$ apresentada no quadro 1.

Quadro 1. Elaboração da pergunta do estudo, segundo a estratégia PICo

\begin{tabular}{|l|c|c|}
\hline Acrônimo & Descrição & Palavras-chave \\
\hline$P$ & População & Agente de Segurança Penitenciária \\
\hline I & Interesse & Assistência prestada em HIV/aids \\
\hline Co & Contexto & Sistema prisional \\
\hline
\end{tabular}

Dessa forma, elaborou-se a seguinte questão norteadora: "Qual o papel do agente de segurança penitenciária na assistência em HIV/aids no sistema prisional?"

Os critérios de inclusão das produções científicas foram: estudos em português, inglês e espanhol; artigos que respondam à questão norteadora do estudo. Excluíram-se artigos duplicados; artigos não encontrados na íntegra; produçóes técnicas (manuais, protocolos); estudos secundários (revisôes).

A busca bibliográfica foi realizada no mês de dezembro de 2020 nas bases de dados: Literatura Latino-Americana e do Caribe em Ciências da Saúde (LILACS), abrange a literatura em ciências da saúde da América Latina e Caribe; MEDLINE, especializada em ciências biomédicas e ciências da vida; Excerpta Medica dataBASE (EMBASE), abrange a literatura biomédica internacional; SciVerse Scopus, propriedade da Elsevier (SCOPUS), que é a maior base de citaçóes e literatura revisada por pares; Cumulative Index to Nursing and Allied Health Literature (CINAHL), indexa periódicos na área de enfermagem e áreas afins; Academic Search Premier (ASP), é um indexador referencial e de textos multidisciplinares; SocINDEX, indexa periódicos e resumos para revistas especializadas em estudos sociológicos. A opção pelas sete bases de dados teve como intuito obter o maior número possível de publicaçóes científicas pertinentes à temática estudada.

Para a busca dos estudos, foram levantados os vocabulários controlados e livres com os termos: 
"HIV ou Síndrome da Imunodeficiência Adquirida" e "agente de segurança penitenciária e suas derivaçôes”, conforme quadro 2 .

Quadro 2. Vocabulários controlados e livres de acordo com a questão norteadora

\begin{tabular}{|c|c|c|}
\hline $\begin{array}{l}\text { Vocabulário controlado } \\
\text { (em negrito) / } \\
\text { Vocabulário livre } \\
\text { (português) }\end{array}$ & $\begin{array}{l}\text { Vocabulário controlado (em negrito) / } \\
\text { Vocabulário livre (inglês) }\end{array}$ & \begin{tabular}{|l|} 
Vocabulário \\
controlado \\
(em negrito) / \\
Vocabulário livre \\
(Espanhol) \\
\end{tabular} \\
\hline $\begin{array}{l}\text { Síndrome de } \\
\text { Imunodeficiência } \\
\text { Adquirida } \\
\text { aids } \\
\text { SIDA } \\
\text { Síndrome da Deficiência } \\
\text { Imunológica Adquirida } \\
\text { Síndrome de Deficiência } \\
\text { Imunológica Adquirida } \\
\text { Síndrome da } \\
\text { Imunodeficiência } \\
\text { Adquirida } \\
\text { Síndrome de } \\
\text { Imunodeficiência } \\
\text { Adquirida } \\
\text { Vírus da Imunodeficiência } \\
\text { Humana } \\
\text { Vírus de Imunodeficiência } \\
\text { Humana }\end{array}$ & $\begin{array}{l}\text { Acquired Immunodeficiency } \\
\text { Syndrome } \\
\text { AIDS } \\
\text { AIDS Vírus } \\
\text { AIDS Víruses } \\
\text { HIV } \\
\text { Human Immunodeficiency Virus } \\
\text { Acquired Immune Deficiency Syndrome } \\
\text { Acquired Immuno Deficiency Syndrome } \\
\text { Acquired Immuno-Deficiency Syndrome } \\
\text { Acquired Immuno-Deficiency Syndromes } \\
\text { Acquired Immunodeficiency Syndromes } \\
\text { Immuno-Deficiency Syndrome, Acquired } \\
\text { Immuno-Deficiency Syndromes, } \\
\text { Acquired } \\
\text { Immunodeficiency Syndrome, Acquired } \\
\text { Immunodeficiency Syndromes, Acquired } \\
\text { Immunologic Deficiency Syndrome, } \\
\text { Acquired } \\
\text { Syndrome, Acquired Immuno-Deficiency } \\
\text { Syndrome, Acquired Immunodeficiency } \\
\text { Syndromes, Acquired Immuno- } \\
\text { Deficiency } \\
\text { Syndromes, Acquired Immunodeficiency }\end{array}$ & $\begin{array}{l}\text { Síndrome de } \\
\text { Inmunodeficiencia } \\
\text { Adquirida } \\
\text { SIDA } \\
\text { Síndrome de } \\
\text { Deficiência } \\
\text { Inmunológica } \\
\text { Adquirida } \\
\text { Síndrome de la } \\
\text { Inmunodeficiencia } \\
\text { Adquirida } \\
\text { Síndrome de } \\
\text { Inmunodeficiencia } \\
\text { Adquirida } \\
\text { VIH } \\
\text { Virus de } \\
\text { Inmunodeficiencia } \\
\text { Humana } \\
\text { Virus de la } \\
\text { Inmunodeficiencia } \\
\text { Humana } \\
\text { Virus del SIDA }\end{array}$ \\
\hline $\begin{array}{l}\text { Agente de Segurança } \\
\text { Penitenciária* } \\
\text { Agente de segurança } \\
\text { penitenciário } \\
\text { Agente penitenciária } \\
\text { Agente penitenciário } \\
\text { Agentes penitenciárias } \\
\text { Agentes penitenciários } \\
\text { Inspetor penitenciário } \\
\text { Guarda prisional } \\
\text { Carcereiro } \\
\text { Inspetor penitenciário }\end{array}$ & $\begin{array}{l}\text { Penitentiary Security Officer* } \\
\text { Penitentiary agent } \\
\text { Penitentiary agents } \\
\text { Prison guards } \\
\text { Prison guard } \\
\text { Prison agentes } \\
\text { Correctional officers } \\
\text { Correctional officer } \\
\text { Correctional workers } \\
\text { Prison officer } \\
\text { Prison officers } \\
\text { Prison inspector } \\
\text { Jail officers } \\
\text { Jail officer } \\
\text { Jailer } \\
\text { Jailor } \\
\text { Warder } \\
\text { Workers prison }\end{array}$ & $\begin{array}{l}\text { Oficial de seguridad } \\
\text { penitenciaria* } \\
\text { Agente penitenciaria } \\
\text { Agente penitenciario } \\
\text { Agentes } \\
\text { penitenciarias } \\
\text { Agentes } \\
\text { penitenciarios } \\
\text { Guardia penitenciario } \\
\text { Oficial correccional } \\
\text { Guardia de la prisión } \\
\text { Guardas de prisión } \\
\text { Carcelero } \\
\text { Inspector } \\
\text { penitenciario }\end{array}$ \\
\hline
\end{tabular}

*Não encontrado vocabulário controlado para este termo

No LILACS, a busca foi realizada com a utilização do vocabulário encontrado nos três idiomas e, nas demais bases de dados, a busca foi realizada com as palavras em inglês. Para proceder às combinaçóes dos descritores e palavras-chave, foram utilizados os operadores booleanos AND e OR, que possibilitaram obter maior especificidade no levantamento bibliográfico. $\mathrm{O}$ operador AND restringiu a busca, uma vez que precisou conter dois termos, enquanto o OR somou os assuntos e ampliou a pes- quisa. Dessa forma, especificamente para essa busca, a combinação ficou da seguinte forma: ((HIV OR "Síndrome da Imunodeficiência Adquirida" OR demais derivaçóes) AND ("agente de segurança penitenciária" OR demais derivaçóes)).

Após o levantamento bibliográfico nas bases de dados, os resultados das buscas foram exportados para o aplicativo de revisão online Rayyan QCRI da Qatar Computing Research Institute (2016), ${ }^{(16)}$ o qual permitiu a eliminação de duplicidades e a seleção das publicaçóes por dois revisores independentes, conforme os critérios de inclusão e exclusão mencionados neste projeto. A seleção foi feita inicialmente pela leitura do título e resumo dos artigos e, quando houve discordância entre os artigos selecionados pelos revisores, estes decidiram em conjunto pela inclusão ou exclusão dos mesmos. Em seguida, foi realizada a leitura na íntegra dos materiais e, sendo estes pertinentes à revisão, iniciou-se a extração de dados mediante a utilização de um instrumento específico. ${ }^{(17)}$ Nos artigos selecionados, foi realizada busca manual nas referências bibliográficas com o intuito de encontrar artigos adicionais que pudessem ser incluídos na presente revisão. Importante destacar que não foram utilizados limites de data de publicação na busca e seleção dos artigos.

\section{Resultados}

Foram recuperadas 3.036 publicações nas bases de dados por meio dos descritores mencionados, sendo 1.278 excluídos por duplicação. Após a leitura dos títulos e resumos de 1.758 publicaçóes, 1.701 foram excluídas. Dessa forma, 57 materiais selecionados foram considerados elegíveis para leitura na íntegra, dos quais foram excluídos 38 por não abordarem o tema proposto, 04 por estarem em outros idiomas, 03 por não terem sido encontrados e 03 por serem estudos de revisão (secundários). Dessa forma, nove artigos foram incluídos neste estudo (Figura 1), por meio dos quais foi realizada uma busca manual de novos artigos nas bibliografias contidas nestes materiais, não foram encontrados estudos adicionais a serem incluídos na revisão. 


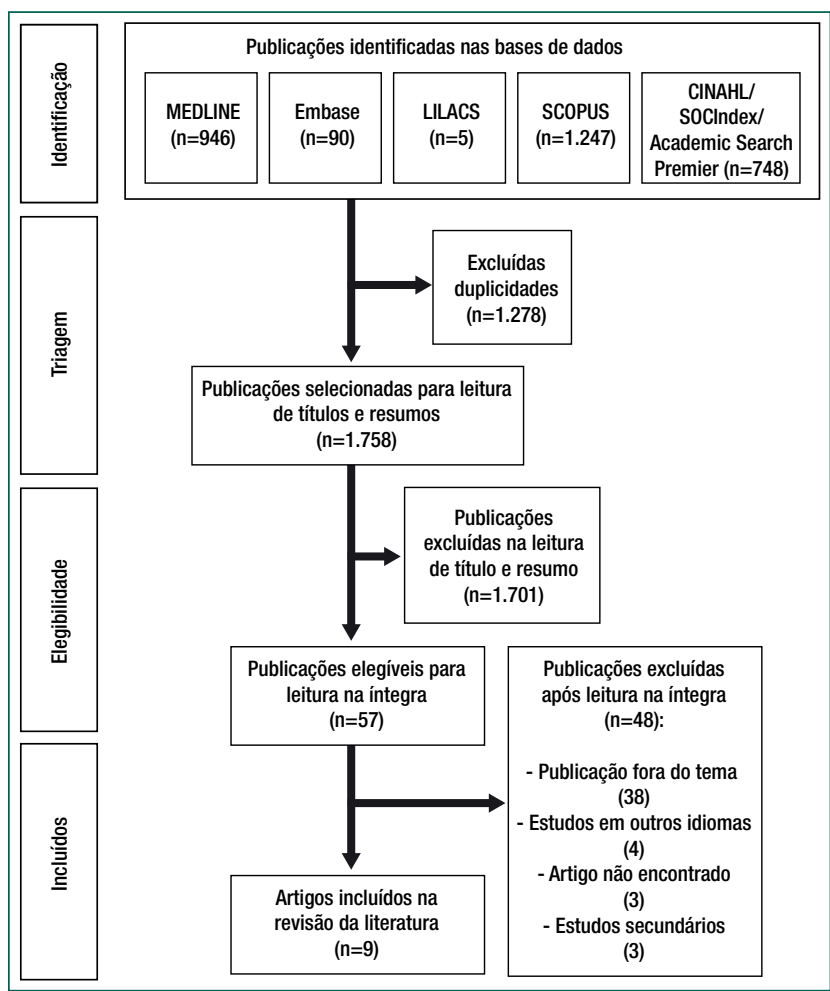

Fonte: Adaptado de Moher D et al. (2009). ${ }^{(18)}$

Figura 1. Fluxograma do número de publicações analisadas em cada etapa da revisão narrativa
Dos nove artigos incluídos nesta revisão, ${ }^{(19-27)}$ todos foram publicados em língua inglesa, sendo três estudos realizados na Zâmbia, ${ }^{(19-21)}$ dois no Canadá, ${ }^{(22,23)}$ um nos Estados Unidos, ${ }^{(24)}$ um no Suriname, ${ }^{(25)}$ um na Polônia, ${ }^{(26)}$ e um no Zimbábue. (27) Os artigos foram publicados entre os anos de 1994 e 2020 (Quadro 3).

Entre os artigos incluídos, cinco eram estudos qualitativos, ${ }^{(20-23,27)}$ dois eram relatos de casos, ${ }^{(19,25)}$ um descritivo ${ }^{(26)}$ e um era estudo com métodos mistos (Quadro 3). ${ }^{(20)}$

Os objetivos e a síntese dos principais resultados encontrados na produção científica referente ao papel do ASP na assistência em HIV/aids no sistema prisional são mostrados no quadro 3.

\section{Discussão}

O ASP pode exercer uma atuação privilegiada no tocante ao desenvolvimento de açóes relacionadas à saúde prisional, com potencial, inclusive, de mudar

Quadro 3. Descrição dos artigos incluídos na revisão narrativa sobre o papel do agente de segurança penitenciária na assistência em HIV/Aids no sistema prisional

\begin{tabular}{|c|c|c|c|c|c|}
\hline $\begin{array}{l}\text { Autores/ Periódico/ } \\
\text { Ano/País }\end{array}$ & $\begin{array}{l}\text { Delineamento } \\
\text { do estudo }\end{array}$ & Objetivo & Total (n) & \begin{tabular}{|l|} 
Instrumento de \\
medida
\end{tabular} & Principais resultados \\
\hline $\begin{array}{l}\text { MacGregor }{ }^{(19)} / \text { Times } \\
\text { Higher Education } \\
\text { Supplement / } 2003 \text { / } \\
\text { Zâmbia }\end{array}$ & $\begin{array}{l}\text { Relato de } \\
\text { Caso* }\end{array}$ & $\begin{array}{l}\text { Relatar acerca do projeto "In But } \\
\text { Free: Prevenção de aids nas Prisões" } \\
\text { que tem como objetivo promover a } \\
\text { prevenção do HIV/aids nas prisões, } \\
\text { usando tanto os presos quanto os } \\
\text { oficiais como agentes-chave. }\end{array}$ & Não se aplica & Não se aplica & $\begin{array}{l}\text { Papel do agente: } \\
\text {-atuar como conselheiro no desenvolvimento de ações de prevenção à } \\
\text { transmissão do HIV no sistema prisional. } \\
\text { (o artigo não apresentou detalhes dessa atuação) }\end{array}$ \\
\hline $\begin{array}{l}\text { Todrys et al.(20) } \\
\text { / Journal of the } \\
\text { international AIDS } \\
\text { Society / } 2011 \text { / } \\
\text { Zâmbia }\end{array}$ & Método misto & $\begin{array}{l}\text { Entender melhor a relação entre as } \\
\text { condições das prisões, os direitos } \\
\text { da justiça criminal e a prevenção, } \\
\text { tratamento e assistência ao HIV e } \\
\text { tuberculose na Zâmbia. }\end{array}$ & $\begin{array}{l}\text { Presos }(n=246) \\
\text { / Agentes } \\
\text { penitenciários } \\
(n=31)\end{array}$ & Entrevistas & $\begin{array}{l}\text { Papel do agente: } \\
\text { - garantir métodos de prevenção da transmissão do HIV nas prisões; } \\
\text { - controlar o acesso aos cuidados. } \\
\text { Aspectos negativos: não são qualificados e formados para avaliar e } \\
\text { determinar se as consultas médicas são necessárias. }\end{array}$ \\
\hline $\begin{array}{l}\text { Topp et al.(21) / Health } \\
\text { Policy and Planning / } \\
2016 \text { / Zâmbia }\end{array}$ & Qualitativo & $\begin{array}{l}\text { Explorar e descrever a dinâmica } \\
\text { institucional e social que influencia } \\
\text { a saúde dos presos e o acesso aos } \\
\text { cuidados de saúde na Zâmbia. }\end{array}$ & $\begin{array}{l}111 \text { entrevistas } \\
\text { (sendo } 79 \\
\text { prisioneiros e } \\
32 \text { com agentes } \\
\text { penitenciários) }\end{array}$ & $\begin{array}{l}\text { Entrevista } \\
\text { semiestruturada }\end{array}$ & $\begin{array}{l}\text { Papel do agente: } \\
\text { - escolher o capitão da cela, o qual controlavam, juntamente com o agente, } \\
\text { o acesso dos presos aos serviços de saúde; } \\
\text { - incentivar o planejamento de visitas clínicas em HIV e reposição de } \\
\text { medicamentos; } \\
\text { - acompanhar os internos da penitenciária para qualquer centro de saúde } \\
\text { público externo ou hospital. } \\
\text { Aspectos negativos: } \\
\text { - suborno dentro das prisões para acessar os serviços. }\end{array}$ \\
\hline $\begin{array}{l}\text { Godin et al.(22) / } \\
\text { Canadian HIV/AIDS } \\
\text { Policy \& Law Review } \\
\text { / } 2001 \text { / Canadá }\end{array}$ & Qualitativo & $\begin{array}{l}\text { Identificar os fatores que influenciam } \\
\text { os agentes penitenciários a concordar } \\
\text { ou se recusar a tornar acessíveis } \\
\text { as ferramentas necessárias para a } \\
\text { prevenção transmissão do HIV entre } \\
\text { os presos. }\end{array}$ & 957 agentes & $\begin{array}{l}\text { Questionário (não } \\
\text { expõe detalhes) }\end{array}$ & $\begin{array}{l}\text { Papel do agente: } \\
\text { - distribuir medidas preventivas necessárias à prevenção da transmissão do HIV } \\
\text { nas prisões (preservativos, equipamentos de tatuagem e seringas estéreis. } \\
\text { Aspectos positivos: } \\
\text { - Mulheres, solteiros, pessoas que trabalham em instituições federais e } \\
\text { pessoas que trabalham em unidades prisionais femininas são mais a favor } \\
\text { da distribuição de tais medidas. } \\
\text { Aspectos negativos: } \\
\text { - apenas } 21,4 \% \text { são a favor de executar esse papel. Pessoas que fizeram } \\
\text { treinamento em HIV e já foram expostas ao risco de infecção por HIV são } \\
\text { mais contrários. } \\
\text { - os oficiais não se consideram como "agentes de prevenção" e sofrem } \\
\text { pressões sociais para não exercerem tal função. }\end{array}$ \\
\hline
\end{tabular}




\begin{tabular}{|c|c|c|c|c|c|}
\hline $\begin{array}{l}\text { Autores/ Periódico/ } \\
\text { Ano/País }\end{array}$ & $\begin{array}{l}\text { Delineamento } \\
\text { do estudo }\end{array}$ & Objetivo & Total (n) & $\begin{array}{l}\text { Instrumento de } \\
\text { medida }\end{array}$ & Principais resultados \\
\hline $\begin{array}{l}\text { Van Der Meulen et } \\
\text { al.(23) / Canadian } \\
\text { Journal of } \\
\text { Criminology and } \\
\text { Criminal Justice / } \\
2018 \text { / Canadá }\end{array}$ & Qualitativo & $\begin{array}{l}\text { Construir um diálogo com o serviço } \\
\text { correcional do Canadá em relação às } \\
\text { medidas de reduçãa de dados nas } \\
\text { prisões - programas de seringas e } \\
\text { agulhas nas prisões (PNSP). }\end{array}$ & $\begin{array}{l}30 \text { Profissionais } \\
\text { de saúde } \\
\text { que atendem } \\
\text { prisioneiros e } 10 \\
\text { ex prisioneiros }\end{array}$ & $\begin{array}{l}\text { Entrevistas e } \\
\text { grupos focais } \\
\text { (não explicou } \\
\text { o instrumento } \\
\text { utilizado) }\end{array}$ & $\begin{array}{l}\text { Papel do agente: } \\
\text { - atuar na redução de danos nas unidades prisionais; } \\
\text { - realizar ações de promoção da saúde dos presos e prevenção da } \\
\text { transmissão de doenças. } \\
\text { Aspectos negativos: } \\
\text { - são resistentes e constituem barreira importante à implantação dos } \\
\text { programas de redução aos danos, opondo-se a administrar ou apoiar tais } \\
\text { programas. } \\
\text { Aspectos positivos: } \\
\text { - são trabalhadores da linha de frente no cenário da prisão, e mantém } \\
\text { contato frequente e direto com os prisioneiros. }\end{array}$ \\
\hline $\begin{array}{l}\text { Mitchell et al. }{ }^{(24)} \text { / } \\
\text { AIDS education and } \\
\text { prevention / } 2015 \text { / } \\
\text { Estados Unidos }\end{array}$ & Qualitativo & \begin{tabular}{|l|} 
Entender melhor as características \\
organizacionais e processos que \\
levam à implementação bem e mal \\
sucedida dos serviços de HIV e \\
tratamento no sistema prisional sob a \\
perspectiva de diferentes e principais \\
interessados.
\end{tabular} & \begin{tabular}{|l|}
17 entrevistas \\
com \\
Pesquisadores \\
Seniors e \\
Patrocinadores \\
Executivos \\
(um de cada \\
categoria e \\
unidade - eram \\
9 unidades) \\
\end{tabular} & \begin{tabular}{|l|} 
Entrevista \\
semiestruturada
\end{tabular} & $\begin{array}{l}\text { Papel do agente: } \\
\text { - permitir o acesso dos detentos às intervenções em grupo de prevenção } \\
\text { ao HIV. } \\
\text { Aspectos negativos: } \\
\text { - falta de cooperação e retaguarda de atores-chave se tornou um desafio } \\
\text { para implementação bem sucedida dos serviços de HIV no sistema } \\
\text { prisional. } \\
\text { Aspectos positivos: até o final do projeto, os agentes superaram essas } \\
\text { barreiras de comunicação e também conheceram aliados que poderiam } \\
\text { ajudar em trabalhos subsequentes }\end{array}$ \\
\hline $\begin{array}{l}\text { Antonius(25) / AIDS } \\
\text { Health Promotion } \\
\text { Exchange / } 1994 \text { / } \\
\text { Suriname }\end{array}$ & $\begin{array}{l}\text { Relato de } \\
\text { Caso* }^{*}\end{array}$ & $\begin{array}{l}\text { Descrever o programa de educação } \\
\text { e apoio em HIV/aids envolvendo } \\
\text { atividades para os reclusos e guardas } \\
\text { prisionais, utilizando como estratégia } \\
\text { o treinamento de educadores pares. }\end{array}$ & Não se aplica & Não se aplica & $\begin{array}{l}\text { Papel do agente: } \\
\text { - receber treinamento sobre prevenção de infecções sexualmente } \\
\text { transmissíveis e HIV/aids; } \\
\text { - atuar como facilitadores das sessões educativas em HIV/aids que foram } \\
\text { realizadas na unidade prisional; } \\
\text { - participaram da seleção e avaliação de vídeos educativos em aids e } \\
\text { infecções sexualmente transmissíveis a serem apresentados mensalmente } \\
\text { aos detentos. } \\
\text { Aspectos negativos: agentes foram pouco colaborativos e alguns se } \\
\text { mostraram inadequados como educadores. }\end{array}$ \\
\hline $\begin{array}{l}\text { Łukaszek }^{(26)} \text { / HIV } \\
\text { AIDS Rev / } 2019 \text { / } \\
\text { Polônia }\end{array}$ & Descritivo & $\begin{array}{l}\text { Definir a situação epidemiológica } \\
\text { sobre as infecções pelo HIV em } \\
\text { estabelecimentos penitenciários } \\
\text { poloneses, mostrar a magnitude dos } \\
\text { comportamentos sexuais de risco } \\
\text { na vida dos presos, que poderiam e } \\
\text { ainda podem provocar infecções por } \\
\text { vírus, mostrar opiniões dos agentes } \\
\text { do Serviço Penitenciário sobre o } \\
\text { problema das infecções pelo HIV entre } \\
\text { os presos (a magnitude do problema } \\
\text { e o papel do Serviço Penitenciário na } \\
\text { prevenção do HIV). }\end{array}$ & $\begin{array}{l}485 \text { homens } \\
\text { que cumprem } \\
\text { pena de prisão } \\
\text { e } 210 \text { agentes } \\
\text { do Serviço } \\
\text { Penitenciário }\end{array}$ & $\begin{array}{l}\text { Questionário } \\
\text { auto-aplicável } \\
\text { elaborado pelo } \\
\text { autor } \bigotimes \text { fez } \\
\text { estudo piloto } \\
\text { antes }\end{array}$ & $\begin{array}{l}\text { Papel do agente: } \\
\text { - fornecimento de preservativos aos presos, mas } 87,1 \% \text { deles achavam } \\
\text { inadequado a execução de tal ação e } 66 \% \text { não concordam nem com } \\
\text { a compra - } 10 \% \text { disseram que os detentos poderiam comprar os } \\
\text { preservativos e apenas } 6,7 \% \text { concordam em doá-los de graça; } \\
\text { - educação sexual dos presos, mas somente } 55,7 \% \text { dos entrevistados } \\
\text { optaram por realizar essas orientações, mas apenas } 16,7 \% \text { dos } \\
\text { profissionais estavam fortemente convencidos sobre sua necessidade. }\end{array}$ \\
\hline $\begin{array}{l}\text { Mhlanga-Gunda et } \\
\text { al.(27) / Int J Prison } \\
\text { Health / } 2020 \text { / } \\
\text { Zimbábue }\end{array}$ & Qualitativo & \begin{tabular}{|l|} 
Investigar as desigualdades de saúde \\
atuais de prisioneiras mulheres \\
e compreender melhor suas \\
experiências de saúde prisional, \\
continuidade de cuidados de saúde \\
em prisões, e em particular, prevenção \\
do HIV, tratamento, apoio e cuidado \\
em prisões zimbabuanas.
\end{tabular} & \begin{tabular}{l|}
13 informantes- \\
chave para as \\
entrevistas; \\
24 detentas \\
mulheres e 24 \\
profissionais do \\
serviço prisional \\
para os grupos \\
focais (cada \\
grupo contava \\
com seis \\
participantes)
\end{tabular} & \begin{tabular}{|l|} 
Guias \\
estruturados \\
para \\
entrevistas com \\
informantes- \\
chave e \\
discussões em \\
grupos focais
\end{tabular} & $\begin{array}{l}\text { Papel do agente: } \\
\text { - prestação de informações sobre educação em saúde; } \\
\text { - atuação no acesso das mulheres encarceradas a atenção primária à } \\
\text { saúde, incluído o acesso aos serviços de HIV. }\end{array}$ \\
\hline
\end{tabular}

*modelo de estudo não descrito no artigo, sendo que a classificação do mesmo foi feita pelos autores da presente revisão

as concepçóes e as práticas assistenciais nesse contexto. ${ }^{(6)}$ Isso ocorre em função da presença numericamente predominante desses profissionais na composição das equipes das unidades prisionais, ${ }^{(12)}$ bem como do maior contato destes com os detentos. ${ }^{(28)}$ Frente a isso, é importante ressaltar uma lacuna na produção de conhecimento científico em relação a tal temática, configurada pela ausência de publicaçóes brasileiras, bem como pela escassez de estudos na literatura internacional sobre o tema em questáo, sendo estas limitadas a apenas seis países (Zâmbia, Canadá, Estados Unidos, Suriname, Polônia e Zimbábue).

Embora os estudos encontrados e selecionados não sejam brasileiros, no Brasil o art. $2^{\circ}$ da Lei ${ }^{\circ}$ 10.693, de 25 de junho de 2003, que cria a carreira de agente penitenciário, prevê sua atuação vinculada às atividades de atendimento, vigilância, custódia, 
guarda, à assistência e orientação de pessoas recolhidas aos estabelecimentos penais e das atividades de natureza técnica, administrativa e de apoio a elas relacionadas. ${ }^{(29)}$ Embora o ASP tenha uma atuação ampla e o país exerça uma posição de destaque na atenção e controle ao HIV/aids no cenário mun$\operatorname{dial}^{(30)}$, as pesquisas desenvolvidas nacionalmente não enfocam o tema em questão e mostra a necessidade da produção de conhecimento voltada a suprir tal ausência.

Cabe destacar ainda que os objetivos propostos nos estudos incluídos na presente revisão não estavam relacionados, especificamente, à identificação do papel do ASP na assistência em HIV/Aids no sistema prisional, de tal forma que informaçôes sobre o tema buscado emergiram nos textos como um resultado secundário apresentado nos estudos. Isso mostra uma lacuna importante na produção de conhecimento acerca do tema estudado, além de ter sido determinante no delineamento narrativo desta revisão.

Os principais resultados encontrados em relação ao papel do ASP na assistência em HIV/aids foram: regulação do acesso aos serviços médicos; ${ }^{(20-22,24,27)}$ colaboração e realização de atividades de prevenção à transmissão do HIV nos presídios; ${ }^{(19,20,22,25-27)}$ acompanhamento de detentos em consultas, exames e internaçóes fora do sistema prisional ${ }^{(20,24)} \mathrm{e}$ planejamento acerca da reposição de medicamentos no sistema prisional. ${ }^{(21)}$

Estudo aponta que o papel do ASP na regulação do acesso aos serviços de saúde é uma ação frequente nas unidades prisionais. ${ }^{(6)}$ Nesse caso, os detentos solicitam atendimento ao agente, seja verbalmente ou por meio de encaminhamento de um bilhete, o qual é julgado pelo mesmo, que direciona o caso ou não à equipe de saúde. ${ }^{(12)}$ Assim como apontado por estudo incluído nesta revisão, tal atuação perpassa pelas limitaçóes de preparo do ASP, os quais não recebem formação e treinamento específico para realizar esse tipo de avaliação. ${ }^{(20)}$

Outro papel do ASP em relação à assistência em HIV/aids envolve açôes de prevenção à transmissão do vírus no ambiente prisional, que pode atuar como um apoiador das equipes de saúde no desenvolvimento de tais açôes ${ }^{(25,27)}$ ou na oferta das mes- mas. ${ }^{(19,20,22,23)}$ Nesse caso, podem atuar como conselheiros em assuntos relacionados à doença ${ }^{(19)}$ e aos modos de prevenir sua transmissão, ${ }^{(26)}$ ação esta que pode ser vinculada à educação sexual, ${ }^{(26)}$ distribuição de preservativos ${ }^{(22,23,26)}$ e açóes de redução de danos, com orientaçôes para o não compartilhamento de equipamentos de tatuagem e seringas estéreis. ${ }^{(22,23)}$ Em relação às barreiras identificadas à efetiva atuação dos ASP na execução de açôes preventivas, propóe-se às equipes de saúde das unidades prisionais, em articulação com a rede de atenção à saúde, que deem retaguarda e participem da formação e educação permanente dos ASP para o desenvolvimento de tais açóes, bem como para a conscientização dos mesmos quanto à importância da atuação no controle do HIV/aids, em função da interface sistema prisional / comunidade; propóe-se também a estes profissionais que motivem os ASP a exercerem tal papel, uma vez que estes não concordam em executar tais ações e costumam temer que diagnosticar doenças resulte em maiores demandas de exames e atendimentos aos presos, bem como maior número de doenças oficialmente reveladas, o que pode levar à implementação de tratamentos que venham impactar na rotina das atividades de segurança. ${ }^{(26)}$

O ASP exerce ainda um papel estratégico na interlocução entre as PPL e as equipes de saúde, uma vez que acompanha o detento nos atendimentos fora das unidades para consultas, realização dos exames e internaçôes ${ }^{(28)}$ e compartilha as informaçôes acerca dessas intervençôes com a equipe de saúde prisional. ${ }^{31)}$

Tal papel colabora com a continuidade do tratamento em HIV/Aids, cuja complexidade de manejo foge do escopo das açóes desenvolvidas pelas unidades de saúde prisionais, uma vez que requer a assistência à doença propriamente dita, bem como às comorbidades, infecçóes oportunistas e eventos adversos do tratamento, o que exige a utilização e o atendimento prestado por serviços de especialidades. ${ }^{(31)}$

Um dos estudos incluídos na presente revisão afirmou que os ASP atuam no planejamento da reposição de medicamentos. ${ }^{(21)}$ Isso ocorre uma vez que estes, em parceria com a equipe de enfermagem, colaboram no processo de dispensação regular da terapia antirretroviral (TARV) aos detentos, 
o que permite, inclusive, estimular e monitorar a adesão ao tratamento, atribuições estas que também são fundamentais para a continuidade da abordagem terapêutica as pessoas que vivem com HIV. ${ }^{(28)}$

Frente ao exposto, o ASP pode ter um papel expressivo na assistência em HIV/Aids, uma vez que as suas atribuições podem ir além das atividades segurança e englobar todo o contexto da unidade prisional. A busca de uma nova identidade livre de estereótipos e preconceitos deve partir da perspectiva de incluir-se como agente de saúde, com o intuito de aumentar a sua participação em açóes de prevenção, de detecção e de acompanhamento dos casos, com implicação direta na melhoria da comunicaçáo e cooperação entre os ASP e equipes de saúde dentro e fora das unidades prisionais, bem como nas condições de vida e de saúde da PPL.

Como limitaçóes do estudo, reitera-se que os objetivos dos estudos incluídos nesta revisão não tinham como enfoque principal a análise do papel do ASP na assistência em HIV/Aids no sistema prisional, sendo que esse papel aparecia como algo secundário aos estudos. Além disso, é importante ressaltar que poucos artigos compuseram essa revisão, bem como sua restrição a estudos internacionais de países diferentes que podem incorrer em diferentes atuaçóes do ASP na assistência em HIV/aids, o que revelou uma lacuna importante no conhecimento relacionado ao tema em questão.

\section{Conclusão}

Os principais papéis desempenhados pelos ASP na assistência em HIV/Aids no sistema prisional incluem a regulação do acesso aos serviços médicos; colaboração e realização de atividade de prevenção à transmissão do HIV nos presídios, como distribuição de preservativos; realização de ações de educação em saúde; acompanhamento dos detentos em consultas, exames e internaçóes fora do sistema prisional; e planejamento de reposição de medicamentos. Em síntese, os estudos que integraram a presente revisão apontam que para garantir e fortalecer a assistência em HIV/aids nas unidades prisionais é necessário considerar o papel do ASP e sua integração à equipe de saúde e, especialmente, junto à equipe de enfermagem no que diz respeito à prestação do cuidado, sendo incluído, estimulado e motivado para tal, seja no apoio ao rastreamento da infecção, ao tratamento ou às medidas de prevenção ou como um elo entre a população prisional e a assistência ofertada dentro e fora do sistema prisional. Nesse sentido, espera-se que este estudo colabore com elementos que ampliem a visão sobre a posição estratégica do papel desse profissional na elaboração conjunta de soluçóes para o controle do HIV/Aids no âmbito prisional para inserí-lo no contexto da assistência e instrumentalizá-lo para incrementar a capacidade de resposta do sistema prisional em relação à prevenção e ao manejo do HIV/ Aids. Por fim, perante as lacunas no conhecimento e ausência de estudos voltados especificamente para o tema em questão, reflete-se sobre a invisibilidade da população privada de liberdade que vive com HIV/ Aids e sugere-se que estudos originais sejam desenvolvidos, em especial no Brasil, a fim de buscar evidências quanto à formação do ASP para a oferta de açóes e serviços à população em questão, bem como do papel deste profissional no que diz respeito à assistência às pessoas infectadas pelo vírus no sistema prisional com enfoque na integração do cuidado e no vínculo com os reeducandos(as) que vivem com HIV/Aids.

\section{Agradecimentos}

O presente trabalho foi realizado com apoio da Coordenação de Aperfeiçoamento de Pessoal de Nível Superior - Brasil (CAPES) - Código de Financiamento 001.

\section{Referências}

1. Joint United Nations Programme on HIV/AIDS at the Brasil. (UNAIDS). Relatório informativo: atualização global da AIDS 2019. Geneva: UNAIDS; 2019 [citado 2020 Out 2]. Disponível em: https://unaids. org.br/wp-content/uploads/2019/07/2019_UNAIDS_GR2019_ FactSheet_pt_final.pdf

2. Brasil. Ministério da Saúde. Secretaria da Saúde. Boletim Epidemiológico HIV/Aids 2020, número especial. Brasília (DF): Ministério da Saúde; 2020 [citado 2020 Dez 6]. Disponível em: http://www.aids.gov.br/ptbr/pub/2020/boletim-epidemiologico-hivaids-2020 
3. Brasil. Ministério da Saúde. Secretaria de Vigilância em Saúde. Departamento de Vigilância. Prevenção e Controle das Infecções Sexualmente Transmissiveis, do HIV/Aids e das Hepatites Virais. Agenda estratégica para ampliação do acesso e cuidado integral das populações-chave em HIV, hepatites virais e outras infecções sexualmente transmissíveis. Brasília (DF): Ministério da Saúde; 2018 [citado 2020 Set 14]. Disponível em: https://portalarquivos2. saude.gov.br/images/pdf/2018/abril/04/Minuta-Agenda-EstrategicaPopulacao-Chave.pdf

4. Nações Unidas sobre Drogas e Crime (UNODC). Prevenção, tratamento, apoio e cuidados com o HIV para pessoas que usam drogas estimulantes: guia técnico. Viena: UNODC; 2019 [cited 2020 Sep 14]. Available from: https://www.unodc.org/documents/lpo-brazil//Topics_ drugs/Publicacoes/GuiaTecnico_HIV_PessoasQueUsamDrogas.pdf

5. Araújo TM, Dias SR, Sousa KA, Silva AA. Vulnerabilidade de pessoas privadas de Liberdade ao vírus da imunodeficiência humana. Rev Cubana Enferm. 2019;34(4):e1571.

6. Diuana V, Lhuilier D, Sánchez AR, Amado G, Araújo L, Duarte AM, et al. Saúde em prisões: representações e práticas dos agentes de segurança penitenciária no Rio de Janeiro, Brasil. Cad Saude Publica. 2008;24(8):1887-96.

7. Valim EM, Daibem AM, Hossne WS. Atenção à saúde de pessoas privadas de liberdade. Rev Bioética. 2018;26(2):282-90.

8. Brasil.MinistériodaJustiçaeSegurançaPública.DepartamentoPenitenciário Nacional. Levantamento Nacional de Informações Penitenciárias - período de julhoa dezembro de 2019. Brasilia(DF):Ministério da Justiçae Segurança Pública; 2019 [citado 2020Ago 3].Disponível em:https://app.powerbi.com/ view?r=eyJrljoiZjA5NDUyZGUtODc1MC00YjczLWEWNGUtYmNhY2Q10 WY2NGU2liwidCI6ImViMDkwNDIwLTQONGMtNDNmNy05MWYyLTRiOG RhNmJmZThIMSJ9

9. Brasil. Ministério da Saúde. Secretaria de Atenção à Saúde Departamento de Ações Programáticas Estratégicas. Plano Nacional de Saúde no Sistema Penitenciário. 2 ed. Brasília (DF): Ministério da Saúde; 2005 [citado 2020 Jun 4]. Disponível em: http://bvsms. saude.gov.br/bvs/publicacoes/plano_nacional_saude_sistema_ penitenciario_2ed.pdf

10. Brasil. Ministério da Saúde. Secretaria de Atenção em Saúde. Departamento de Ações Programáticas Estratégicas. Legislação em saúde no sistema penitenciário. Brasília (DF): Ministério da Saúde; 2010 [citado 2020 Jun 4]. Disponível em: http://bvsms.saude.gov.br/ bvs/publicacoes/legislacao_saude_sistema_penitenciario.pdf

11. Brasil. Ministério da Justiça e Segurança Pública. Departamento Penitenciário Nacional. Levantamento Nacional de Informações Penitenciárias - atualização Junho 2017. Brasília (DF): Ministério da Justiça e Segurança Pública; 2019 [citado 2020 Jun 4]. Disponível em: https://www.gov.br/depen/pt-br/sisdepen/mais-informacoes/ relatorios-infopen/relatorios-sinteticos/infopen-jun-2017.pdf/view

12. Catoia EA. Oferta de ações e serviços de saúde às pessoas privadas de liberdade que vivem com HIV em unidades prisionais de dois municípios do interior paulista [tese]. Ribeirão Preto (SP): Universidade de São Paulo; 2019.

13. Graça BC, Mariano MM, Gusmão MA, Cabral JF, Nascimento VF, Gleriano JS, et al. Dificuldades das mulheres privadas de liberdade no acesso aos serviços de saúde. Rev Bras Promoção Saúde. 2018;31(2):1-9

14. Noble H, Smith J. Reviewing the literature: choosing a review design [Editorial]. Evid Based Nurs. 2018;21(2):39-41.
15. Aromataris E, Munn Z, editors. Joanna Briggs Institute Reviewer's Manual. Melbourne: The Joanna Briggs Institute; 2017 [cited 2020 Jun 4]. Available from https://jbi.global/sites/default/files/2019-01/ JBI_Annual_Report_2017.pdf

16. Mourad O, Hossam H, Zbys F, Ahmed E. Rayyan: a web and mobile app for systematic reviews. Syst Rev. 2016;5(1):210.

17. Ursi ES. Prevenção de lesões de pele no perioperatório: revisão integrativa da literatura [dissertação]. Ribeirão Preto (SP): Universidade de São Paulo; 2005 [citado 2020 Jun 4]. Disponível em: https://doi. org/10.11606/D.22.2005.tde-18072005-095456

18. Moher D, Liberati A, Tetzlaff J, Altman DG; PRISMA Group. Preferred reporting items for systematic reviews and meta-analyses: the PRISMA statement. PLoS Med. 2008;6(7):e1000097.

19. MacGregor K. Freeing prisoners from the threat of infection. Times Higher Education Supplement. 2003;(1604):9.

20. Todrys KW, Amon JJ, Malenka G, Clayton M. Imprisoned and imperiled: access to HIV and TB prevention and treatment, and denial of human rights, in Zambian prisons. J Int AIDS Soc. 2011;14:8.

21. Topp SM, Moonga CN, Luo N, Kaingu M, Chileshe C, Magwende G, et al. Exploring the drivers of health and healthcare access in Zambian prisons: $\mathrm{a}$ health systems approach. Health Policy Plan. 2016;31(9):1250-61.

22. Godin G, Alary M, Morissette M, Noël L. Correctional officers and prevention of HIV transmission among prisoners. Can HIV AIDS Policy Law Rev. 2001;6(1-2):70-1.

23. Van der Meulen E, Reece R, Chu SK. Building dialogue on prison health: Improving access to harm reduction in federal prisons. Canadian $\mathrm{J}$ Criminol Criminal Justice. 2018;60(3):299-313.

24. Mitchell SG, Willett J, Swan H, Monico LB, Yang Y, Patterson YO, et al. Defining success: insights from a random assignment, multisite study of implementing hiv prevention, testing, and linkage to care in U.S. Jails and prisons. AIDS Educ Prev. 2015;27(5):432-45.

25. Antonius C. HIV / AIDS and STD prevention in Surinamese prisons. AIDS Health Promot Exch. 1994;(4):3-5.

26. Łukaszek M. HIV/AIDS - the problem in Polish prisons. HIV \& AIDS Review. 2019;18(3):199-206.

27. Mhlanga-Gunda R, Kewley S, Chivandikwa N, HoutMC. Prison conditions and standards of health care for women and their children incarcerated in Zimbabwean prisons. Int J Prison Health. 2020;16(3):319-36.

28. Ravanholi GM, Catoia EA, Andrade RL, Lopes LM, Brunello ME, Bollela VR, et al. People living with HIV/AIDS in prison: regular use of antiretroviral therapy. Acta Paul Enferm. 2019;32(5):521-9.

29. Brasil. Câmara dos Deputados - Palácio do Congresso Nacional - Praça dos Três Poderes. Lei no 10.693, de 25 de junho de 2003. Cria a Carreira de Agente Penitenciário Federal no Quadro de Pessoal do Ministério da Justiça e dá outras providências. Brasília (DF): Diário Oficial da União, Seção 1, 26 de junho de 2003, Página 1 [citado 2020 Set 15]. Disponível em: https://www2.camara.leg.br/legin/fed/lei/2003/lei-10693-25-junho2003-496982-publicacaooriginal-1-pl.html

30. Melo EA, Maksud I, Agostini R. Cuidado, HIV/Aids e atenção primária no Brasil: desafio para a atenção no Sistema Único de Saúde? Rev Panam Salud Pública. 2018;42:e151.

31. Cadamuro AC, Andrade RL, Lopes LM, Neves LA, Catoia EA, Monroe AA. Coordination of care for people living with HIV in the prison system. Acta Paul Enferm. 2020;33:eAPE20190267. 